\title{
SERUM ALANINE AMINOTRANSFERASE LEVEL AS AN EARLY INDICATOR OF METABOLIC DISTURBANCIES IN WOMEN WITH POLYCYSTIC OVARY SYNDROME (PCOS)
}

Jelica Bjekic-Macut ${ }^{1}$, Ivana Bozic Antic ${ }^{2}$, Konstatinos Tziomalos ${ }^{3}$, Dusan Ilic $^{2}$,

Danijela Vojnovic Milutinovic ${ }^{4}$, Olivera Stanojlovic ${ }^{5}$, Bojana Popovic ${ }^{2}$, Tamara Bogavac ${ }^{2}$, Tatjana Isailovic ${ }^{2}$, Valentina Elezovic ${ }^{2}$, Sanja Ognjanovic ${ }^{2}$, Djuro Macut ${ }^{2}$, Dimitrios Panidis ${ }^{3}$

${ }^{1} \mathrm{CHC}$ Bezanijska kosa, Belgrade, Serbia, ${ }^{2}$ Clinic of Endocrinology, Diabetes and Metabolic Diseases, Clinial Center of Serbia, Belgrade, Serbia, ${ }^{3}$ Department of Medicine, University of Thessaloniki, Greece, ${ }^{4}$ IBISS, University of Belgrade, Serbia,

${ }^{5}$ Institute of Physiology, Faculty of Medicine, University of Belgrade, Serbia

Serum alanine aminotransferase (ALT) level is used to screen patients for unsuspected liver disease. The entire histologic spectrum of nonalcoholic fatty liver disease (NAFLD) can be seen in individuals with normal ALT values. Accordingly, it has been suggested that by using ALT $>19 \mathrm{U} / \mathrm{L}$, early stages of NAFLD could be detected. As it was established a relation of NAFLD and PCOS, the aim of our study was to compare metabolic characteristics of women with polycystic ovary syndrome (PCOS) in relation to ALT levels.

\section{Methods}

Results

We evaluated 600 PCOS women diagnosed using ESHRE/ASRM criteria, divided into 2 groups: group A with ALT<19 IU/L ( $N=299 ; B M I ~ 28.64 \pm 5.86 \mathrm{~kg} / \mathrm{m}^{2}$; age $25.27 \pm 5.77$ years) and group $B$ with ALT $\geq 19 \mathrm{IU} / \mathrm{L}$ $\left(\mathrm{N}=301 ; \mathrm{BMl}: 32.64 \pm 7.36 \mathrm{~kg} / \mathrm{m}^{2}\right.$; age $25.93 \pm 6.12$ years), and 53 healthy non-obese women (Controls: $24.05 \pm 3.29 \mathrm{~kg} / \mathrm{m}^{2} ; 30.21 \pm 5.57$ years). Serum liver enzymes, glucose, insulin, lipids, total testosterone and sex hormone binding globulin were determined. Insulin resistance was evaluated by homeostatic model (HOMA-IR). All analysis were BMI adjusted.

In all examined subjects, liver enzymes were in the reference range. Group B had higher values of aspartate-aminotransferase (AST) $(22.75 \pm 8.85$ vs. $16.73 \pm 3.60, p<0.001)$, gamma-glutamil-transferase $(20.03 \pm 10.93$ vs. $13.40 \pm 5.80, p=0.009)$, alkaline phosphatase $(78.52 \pm 21.36$ vs. $68.28 \pm 20.26, p<0.001)$, insulin (18.46 \pm 10.24 vs. $13.48 \pm 8.83, \mathrm{p}<0.001)$, HOMA-IR ( $4.52 \pm 2.78$ vs. $3.21 \pm 2.26, \mathrm{p}<0.001)$, total cholesterol ( $5.15 \pm 1.02$ vs. $4.70 \pm 0.94, p<0.001)$, $\operatorname{LDL}(3.33 \pm 0.94$ vs. $2.97 \pm 0.82, p<0.001)$ and triglycerides $(1.24 \pm 0.60$ vs. $0.97 \pm 0.40, p<0.001)$. There were no difference in fasting glucose, $H D L$, testosterone and SHBG.

$\mathrm{mmol} / \mathrm{L}$

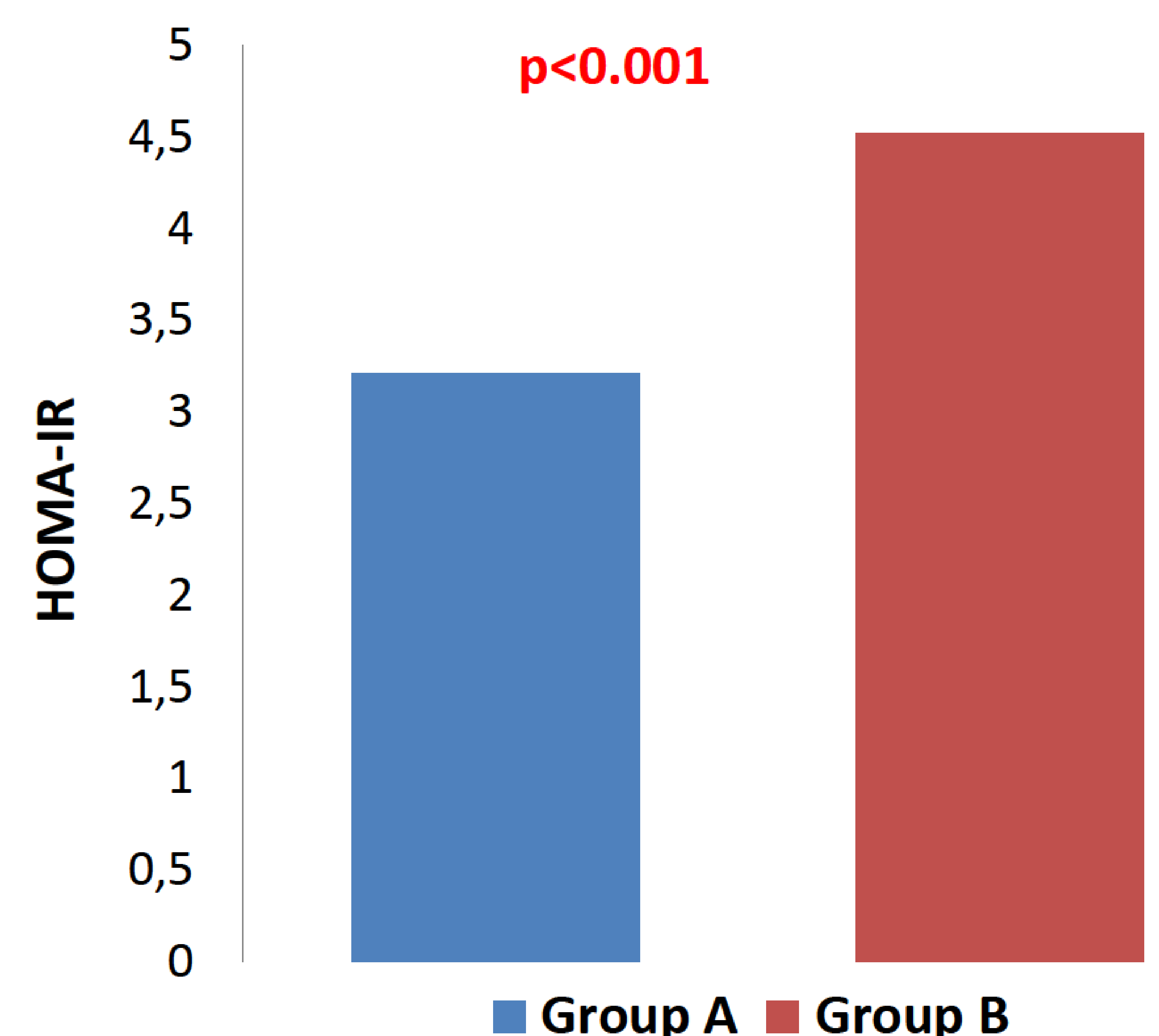

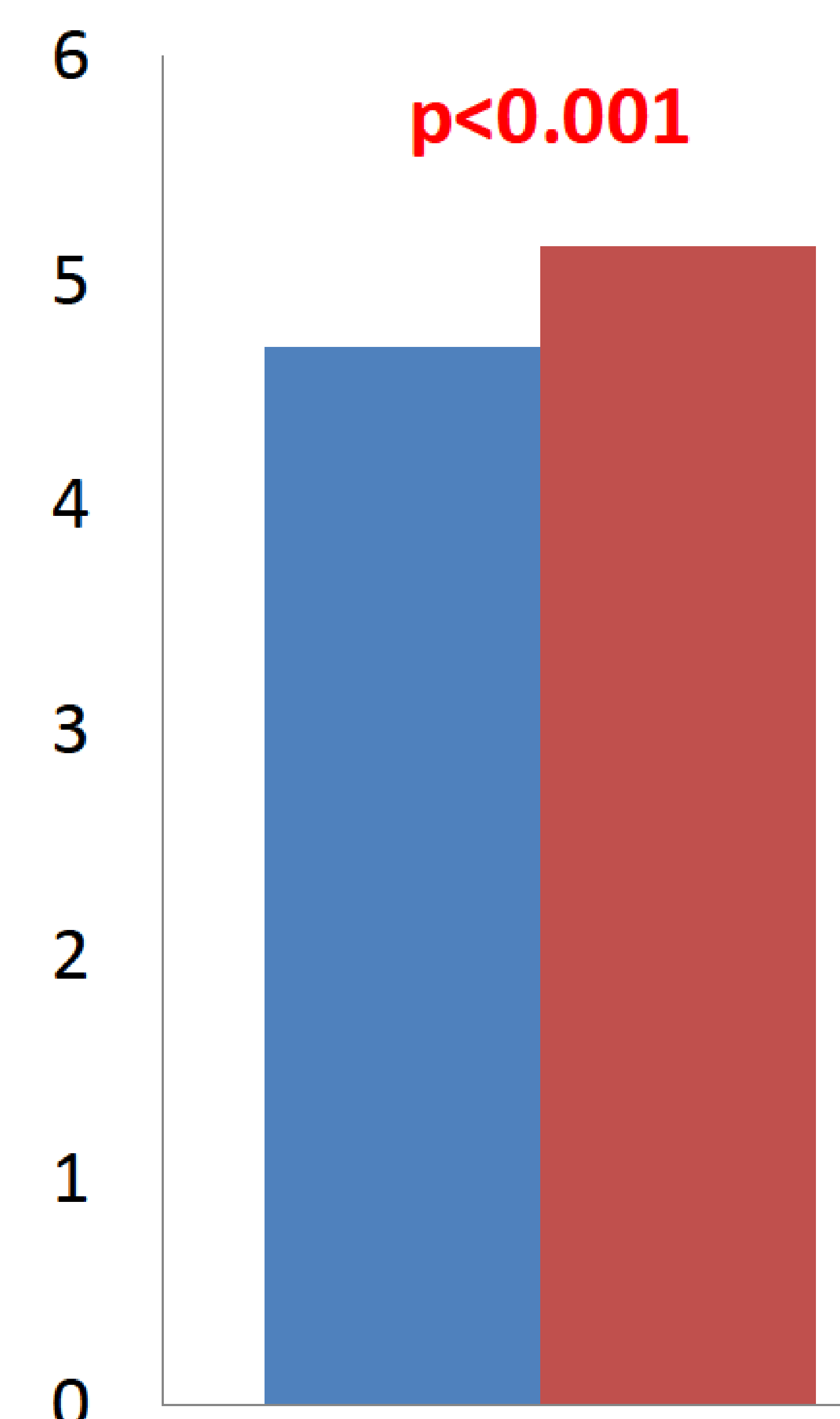

TC

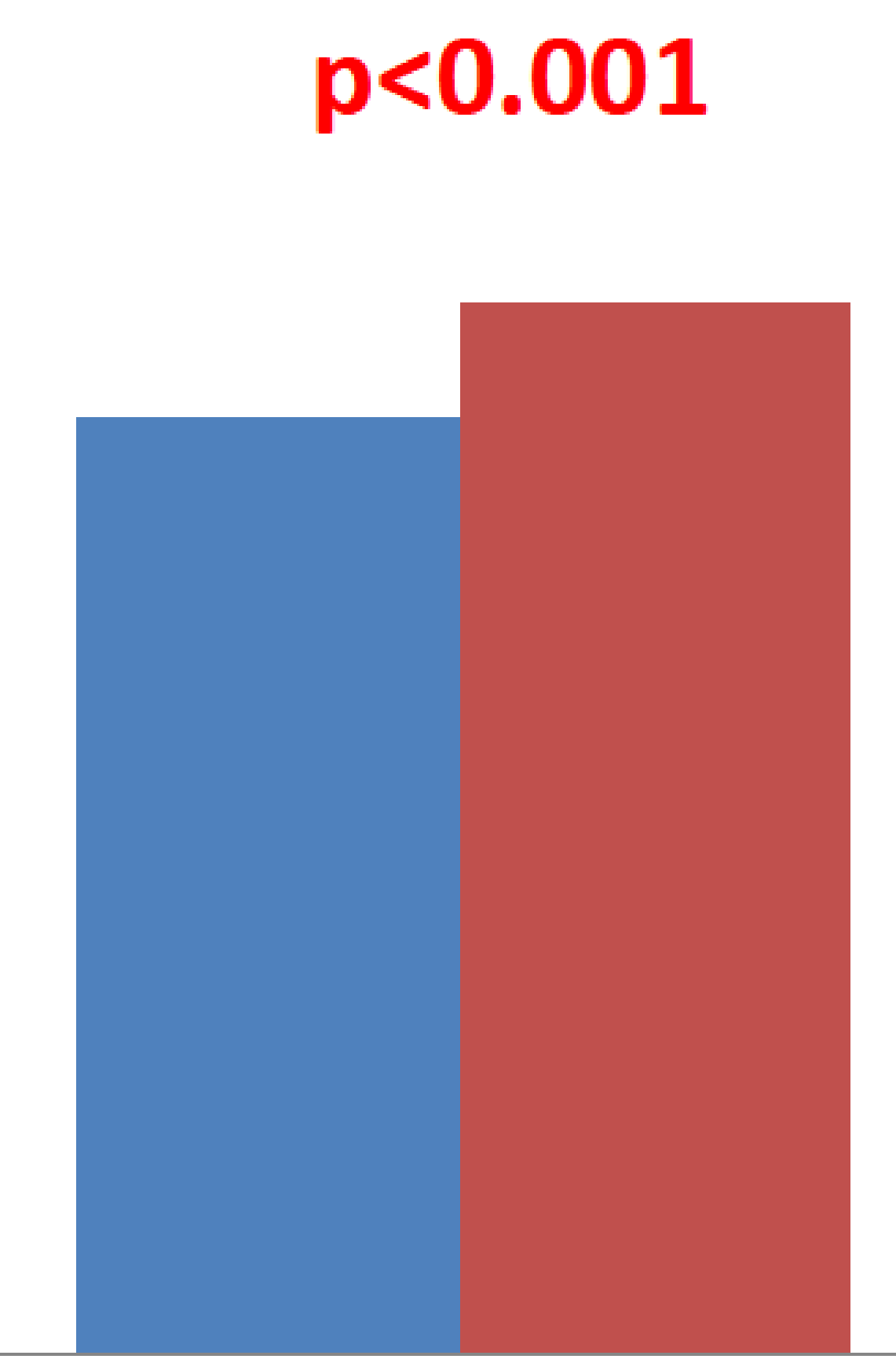

LDL $p<0.001$

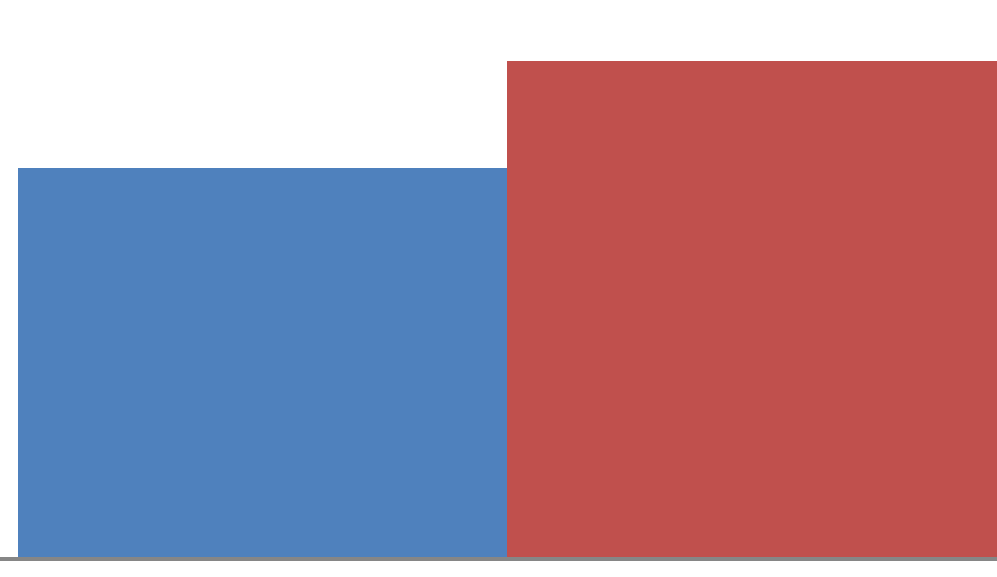

TG

Group A Group B with PCOS. 